DOI: https://doi.org/10.24867/05EF04Karan

\title{
UKLANJANJE ORGANSKOG ZAGAĐENJA IZ OTPADNOG SREDSTVA ZA VLAŽENJE
}

\section{REMOVAL OF ORGANIC POLLUTION FROM THE WASTE FOUNTAIN SOLUTION}

\author{
Jelena Karan, Savka Adamović, Fakultet tehničkih nauka, Novi Sad
}

\section{Oblast - GRAFIČKO INŽENJERSTVO I DIZAJN}

Kratak sadržaj- Karakterizacija efluenta procesa ofset štampe sprovedena je kroz određivanja profila organskog opterećenja i indeksa ugljovodonika otpadnog sredstva za vlaženje primenom gasno hromatografsko/maseno spektrometrijske metode $i$ metode gasne hromatografije, redom. Cilj rada je ispitivanje mogućnosti uklanjanja organskog opterećenja iz otpadnog sredstva za vlaženje primenom adsorpcije sa aktivnim ugljem.

Ključne reči: Ofset štampa, Sredstvo za vlaženje, Efluent, Organske zagađujuće supstance, Adsorpcija.

Abstract -Characterization of the offset printing effluent was carried out through the determination of the organic load profiles and the hydrocarbon index of the waste fountain solution using the gas chromatographic/mass spectrometric method and the gas chromatography method, respectively. The paper aim is to investigate the possibility of removing organic pollutants from the waste fountain solution using adsorption with activated carbon.

Keywords: Offset printing, Fountain solution, Effluent, Organic pollutants, Adsorption.

\section{UVOD}

Jedan od najkompleksnijih globalnih ekoloških problema je zagađenje voda koje je poraslo sa porastom stanovništva, razvojem naselja i industrijalizacijom. Od ukupnih otpadnih voda $30 \%$ su industrijske otpadne vode. Sastav otpadnih voda kao i količina se menja u zavisnosti od industrije u kojoj je generisana, ali se često menja i unutar jedne iste industrije kao posledica primene različitih sirovina, sredstava ili režima rada [1].

Ukoliko se industrijske vode ispuštaju u prirodne recipijente, zakonskim regulativama je propisano da se moraju prečistiti do određenog nivoa. Sa druge strane, ukoliko se otpadne vode ispuštaju u gradsku kanalizaciju, moraju se prečistiti do nivoa kojim neće znatno narušiti kvalitet sanitarnih otpadnih voda, sa kojima se mešaju u kanalizacionom sistemu.

Jedna od najisplativijih, ali i najbržih štamparskih tehnika je ofset štampa [2]. Pre samog procesa štampe, neophodno je pripremiti sredstvo za vlaženje čiji je sastav jedan od ključnih elemenata za kvalitetnu i stabilnu reprodukciju u samoj štampi. Sredstvo za vlaženje je usko povezano i sa grafičkom bojom, , podlogom i štampar-

\section{NAPOMENA:}

Ovaj rad proistekao je iz master rada čiji mentor je bila dr Savka Adamović, docent. skom formom, i kao rezultat njihove međusobne kompleksne interakcije nastaje otpadno sredstvo za vlaženje. Kako površinska hemija igra važnu ulogu u procesu ofset štampe, neophodno je proučavanje hemijskih osobina, sastava i zagađenja otpadnog sredstva za vlaženje, kao i pronalaženje adekvatnog tretmana za prečišćavanje generisanog otpadnog sredstva za vlaženje pre njegovog odlaganja u grafičko okruženje [3].

$\mathrm{U}$ radu je izvršena karakterizacija efluenta procesa ofset štampe kroz određivanja profila organskog opterećenja i indeksa ugljovodonika otpadnog sredstva za vlaženje primenom gasno hromatografsko/maseno spektrometrijske metode i metode gasne hromatografije, redom. Osnovni cilj rada je ispitivanje mogućnosti uklanjanja organskog opterećenja iz otpadnog sredstva za vlaženje primenom adsorpcije radi bezbednog odlaganja tretiranog ofset efluenta u grafičko okruženje.

\section{EKSPERIMENTALNI DEO}

\subsection{Karakterizacija otpadnog sredstva za vlaženje}

Otpadno sredstvo za vlaženje (OSV) u količini od 20 L uzorkovano je iz rezervoara četvorobojne mašine za ofset štampu (Heidelberg Speedmaster 52, Nemačka) iz štamparije na teritoriji Novog Sada. OSV je nastalo tokom procesa ofset štampe u međusobnoj inreakciji četiri komponete: čistog sredstva za vlaženje (FountMax Blue $30.30 \mathrm{AF}$ ), ofset štamparke forme, procesinih grafičkih boja (cijan, magenta, žute i crne) i podloge za štampu (papira).

OSV je tečnost, tamno sive boje, blagog alkoholnog mirisa, temperature $23^{\circ} \mathrm{C}, \mathrm{pH}$ vrednosti 8 , električne

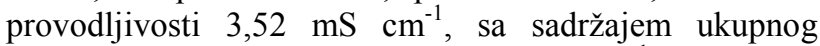
organskog ugljenika (UOU) od $2700 \mathrm{mg} \mathrm{L}^{-1}$, biološkom potrošnjom kiseonika $\left(\mathrm{BPK}_{5}\right)$ od $1500 \mathrm{mg}^{-1}$ i hemijskom potrošnjom kiseonika (HPK) od $810 \mathrm{mg} \mathrm{L}^{-1}$.

2.2. Analiza profila organskog opterećenja otpadnog sredstva za vlaženje

Kvalitativnom gasno hromatografsko/maseno spektrometrijskom (GC/MS) analizom definisan je profil organskog opterećenja OSV. Analiza je sprovedena upotrebom gasnog hromatografa sa masenim detektorom i sa hromatografskom kolonom Agilent J\&W Scientific DB5MS. Za gas nosač upotrebljen je helijum. Pri temperaturi injektora od $270^{\circ} \mathrm{C}$ ubrizgavani su uzorci, dok je temperatura detektora bila $150^{\circ} \mathrm{C}$.

Za pripremu uzoraka OSV upotrebljene su dve metode tečno/tečne (T/T) ekstrakcije: T/T ekstrakcija sa metilen- 
hloridom i sekvencijalna $\mathrm{T} / \mathrm{T}$ ekstrakcija sa n-pentanom, dihlormetanom i dihlormetanom pri $\mathrm{pH}$ vrednosti 2 [4].

Za izradu GC/MS profila organskih supstanci OSV upotrebljen je softver za dekonvoluciju, DRS (eng., Deconvolution Reporting Software). Za identifikaciju organskih supstanci upotrebljen je softver AMDIS (eng., Automated Mass Spectral Deconvolution and Identification System). U cilju preciznije identifikacije svi AMDIS maseni spektri upoređeni su sa referentnim spektrima NIST (eng., National Institute of Standards and Technology) baze podataka. Prisustvo ogranskog jedinjenja u uzorku OSV je dokazano samo ukoliko je verovatnoća njegovog prisustva, dobijena pomoću AMDIS softvera i NIST baze podataka, veća od 70\%. Takođe, hromatogram identifikovanog organskog jedinjenja je ručno pregledan i upoređen sa hromatogramom slepe probe n-pentanske, dihlormetanske i dihlormetanske pri $\mathrm{pH}$ vrednosti 2 frakcije, bi se otklonila mogućnost dobijanja lažno pozitivnih rezultata, tj. prisustva organskog jedinjenja u uzorku, dok je isto prisutno i u slepoj probi. Dodatna potvrda identifikacije organskih jedinjenja poređenjem sa hromatogramima čistih standarda nije urađena, jer je OSV multikomponentni matriks.

\subsection{Određivanje indeksa ugljovodonika otpadnog sredstva za vlaženje}

Za određivanje indeksa ugljovodonika OSV u prvoj metodi T/T ekstrakcije 1L OSV ekstrahovan je sa metilen-hloridom. U drugoj sekvencijalnoj T/T ekstrakciji, 1L OSV je paralelno ekstrahovan u n-pentanu, dihlormetanu i dihlormetanu pri $\mathrm{pH}$ vrednosti 2 . U obe metode T/T ekstrakcije, uzorci OSV su ekstrahovani sa odgovarajućim rastvaračima pri realnoj $\mathrm{pH}$ vrednosti OSV 8,0 i pH vrednosti 2 koja je podešena dodavanjem koncentrovane $\mathrm{HCl}$. Posle ekstrakcije sa odgovarajućim rastvaračima $0,5 \mathrm{~mL}$ ekstrakta preneto je u vijal i analizirano primenom gasno hromatografske (GC) metode. Hromatogram slepe probe, tj. dejonizovane vode (koji je prošla istu proceduru pripreme po obe metode kao i uzorci OSV u određenom ekstrakcionom sredstvu) upotrebljen je za korekciju površine uzoraka.

Indeks ugljovodonika u OSV uzorcima određen je prema jednačini (1) [5]:

$$
\rho=\frac{\left(A_{m}-b\right) f V w}{a\left(m_{1}-m_{2}\right)} R
$$

gde su: $\rho$ - indeks uljovodonika $\left(m g \mathrm{~L}^{-1}\right), \mathrm{A}_{\mathrm{m}}-$ integraljena površina pikova (u jedinicama specifičnim za aparat), b - odsečak na y-osi (u jedinicama specifičnim za aparat), f - faktor razblaženja za ekstrakt uzorka, V zapremina krajnjeg ekstrakta $(\mathrm{mL}), \mathrm{w}$ - gustina vode za uzorak (1,00 $\left.\mathrm{g} \mathrm{mL}^{-1}\right)$, a - nagib kalibracione krive $(1,74 \mathrm{~L}$ $\left.\mathrm{mg}^{-1}\right), \mathrm{m}_{1}$ - masa pune boce za uzimanje uzorka $(\mathrm{g}), \mathrm{m}_{2}-$ masa prazne boce za uzimanje uzorka $(\mathrm{g}),\left(\mathrm{m}_{1}-\mathrm{m}_{2}\right)-$ razlika masa za koju se na osnovu gustine vode aproksimativno uzima da je 1000 g i R - razblaženje uzorka.

\subsection{Adsorpcioni tretman otpadnog sredstva za vlaženje}

Za uklanjanje organskih supstanci iz OSV upotrebljen je aktivni ugalj Norit w35, u obliku crnog praha, bez mirisa, gustine od 0,250 do $0,600 \mathrm{~g} \mathrm{~cm}^{-3}$ i $\mathrm{pH}$ vrednosti rastvora od 6 do 9 .

$\mathrm{U}$ kivete od $45 \mathrm{~mL}$ odmerena je smeša određene mase aktivnog uglja Norit w35 i $25 \mathrm{~mL}$ OSV. Odabrane mase aktivnog uglja od $0,5,0,625,0,75,1,5,2$ i $2,5 \mathrm{~g}$ odgovaraju dozama od 20, 25, 30, 60, $80 \mathrm{i} 100 \mathrm{~g} \mathrm{~L}^{-1}$, redom. U vremenu od 5, 15, 30, 60, 120, 360, 1440 i 2880 minuta smeša Norit w35 i OSV je podvrgnuta kontinualnom mešanju na mešalici sa brzinom mešanja od 150 obrtaja/minuti.

Efikasnosti adsorpcije za uklanjanje organskih supstanci iz OSV sa aktivnim ugljem Norit w35 određene su primenom jednačine (2) [3]:

$$
E_{A C}=\frac{\left(C_{o}-C_{t}\right)}{C_{o}} 100(\%)
$$

gde su: $\mathrm{E}_{\mathrm{AC}}$ - efikasnost uklanjanja (\%) UOU iz OSV primenom aktivnog uglja Norit w35, $\mathrm{C}_{\mathrm{o}}$ - inicijalna koncentracija $\left(2700 \mathrm{mg} \quad \mathrm{L}^{-1}\right)$ UOU u OSV pre adsorpcionog tretmana sa aktivnim ugljem Norit w35 i $\mathrm{C}_{t}$ - koncentracija (mg L ${ }^{-1}$ ) UOU u OSV posle adsorpcionog tretmana sa odgovarajućom dozom aktivnog uglja Norit w35 u određenom vremenu kontakta (adsorpciono vreme) Norit w35 i OSV.

$\mathrm{Na}$ ispitivani adsorpcioni sistem OSV i aktivnog uglja Norit w35 primenjena je kinetičks studija sa reakcionim modelim pseudo-prvog reda (jednačina 3) i pseudodrugog reda (jednačina 4).

$$
\ln \left(q_{e}-q_{t}\right)=\ln q_{e}-k_{1} t
$$

Parametri zavisnosti: $\ln \left(\mathrm{q}_{\mathrm{e}}-\mathrm{q}_{\mathrm{t}}\right)=f(\mathrm{t})$, nagib: $k_{1}\left(\min ^{-1}\right) \mathrm{i}$ odsečak: $\mathrm{q}_{\mathrm{e}}\left(\mathrm{mg} \mathrm{g}^{-1}\right)$.

$$
\frac{t}{q_{t}}=\frac{1}{k_{2} q_{e}}+\frac{1}{q_{e}} t
$$

Parametri zavisnosti: $\mathrm{t} / \mathrm{q}_{\mathrm{t}}=f(\mathrm{t})$, nagib: $\mathrm{q}_{\mathrm{e}}\left(\mathrm{mg} \mathrm{g}^{-1}\right) \mathrm{i}$ odsečak: $k_{1}\left(\mathrm{~g} \mathrm{mg}^{-1} \mathrm{~min}^{-1}\right)$.

\section{REZULTATI I DISKUSIJA}

Nakon kvalitativne i kvantitativne analize organskog opterećenja OSV, primenom adsorpcije na aktivnom uglju ispitana je efikasnost uklanjanja organskog opterećenja radi bezbednog odlaganja tretiranog ofset efluenta $u$ grafičko okruženje.

\subsection{Profil organskog opterećenja otpadnog sredstva za vlaženje}

Kvalitativnim GC/MS profilom posle T/T ekstrakcije sa metilen-hloridom utvrđeno je prisustvo u OSV 31 organske supstance koje pripadaju sledećim klasama jedinjenja: policikličnim aromatičnim ugljovodonicima (4), alkoholima (3), etrima (7), ketonima (1), fenolima (2), supstituisanim benzenima i derivatima benzena (3), organskim kiselinama (5), estrima organskih kiselina (2), amidima organskih kiselina (2), organoazotnim jedinjenjima (1) i aminima (1).

Posle sekvencijalne $\mathrm{T} / \mathrm{T}$ ekstrakcije sa n-pentanom, dihlormetanom $\mathrm{i}$ dihlormetanom pri $\mathrm{pH}=2$, kvalitativni 
GC/MS profil pokazao je prisutvo 59 organskih supstanci u OSV koje pripadaju sledećim klasama jedinjenja: višim alkanima sa C20 do C30 atoma (8), nezasićenim alkenim srednje dužine sa C10 do C20 atoma (2), alkoholima (4), etrima (7), ketonima (3), fenolima (5), supstituisanim benzenima i derivatima benzena (9), organskim kiselinama (4), estrima organskih kiselina (7), amidima organskih kiselina (2), organoazotnim jedinjenjima (2), organskim jedinjenjima sa azotom i kiseonikom (3), organofosfornim jedinjenjima (1), aminima (1) i steroidima (1).

Komparacija GC/MS profila dobijenih T/T metodama sa jednim rastvaračem $i$ sa tri rastvarača pokazuje da sveobuhvatniji organski profil daje sekvencijalna $\mathrm{T} / \mathrm{T}$ ekstrakcija sa rastvaračima n-pentanom, dihlormetanom i dihlormetanom pri $\mathrm{pH}=2 \mathrm{u}$ odnosu na $\mathrm{T} / \mathrm{T}$ ekstrakciju sa jednim rastvaračem. Dakle, sekvencijalnom $\mathrm{T} / \mathrm{T}$ ekstrakcijom se detektuje $47 \%$ više organskih supstanci u odnosu na $\mathrm{T} / \mathrm{T}$ ekstrakciju sa metilen-hloridom. Takođe, PAH jedinjenja su detektovana samo $\mathrm{T} / \mathrm{T}$ ekstrakcijom sa metilen-hloridom, dok su ugljovodonici i organska jedinjenja sa azotom i kiseonikom detektovani samo sekvencijalnom T/T ekstrakcijom. Znači da priroda rastvarača za ekstrakciju utiče na klasu organskih jedinjenja koja će biti ekstrahovana.

Zbog razlika u GC/MS profilima dobijenih $\mathrm{T} / \mathrm{T}$ ekstrakcijom sa jednim rastvaračem (I metod) i sekvencijalnom T/T ekstrakcijom (II metod), a u cilju dobijanja profila sa većim brojem detektovanih organskih supstanci, konačan profil organskog opterećenja je zbirni profil GC/MS profila obe T/T ekstrakcione metode koji sadrži 74 organske supstance sa verovatnoćom prisustva većom od $70 \%$, dobijenih primenom AMDIS softvera za identifikaciju organskih supstanci i NIST referentne baze podataka.

\subsection{Indeks ugljovodonika otpadnog sredstva za vlaženje}

Vrednosti indeksa ugljovodonika $(\rho)$ ekstrakata OSV u odgovarajućim rastvaračima i $\mathrm{pH}$ vrednostima, kao i ukupni indeksi ugljovodonika $\left(\rho_{\mathrm{uk}}\right)$ OSV po metodi T/T ekstrakcije sa metilen-hloridom (I metod) i metodi sekvencijalne T/T ekstrakcije (II metod) sa n-pentanom, dihlormetanom i dihlormetanom pri $\mathrm{pH}=2$ prikazani $\mathrm{su} \mathrm{u}$ tabeli 1.

Tabela 1. Indeksi ugljovodonika otpadnog sredstva za vlaženje

\begin{tabular}{|c|c|c|c|}
\hline OSV ekstrakt sa & \multirow{2}{*}{ Metod } & $\begin{array}{c}\rho \\
\left(\mathrm{mg} \mathrm{L}^{-1}\right)\end{array}$ & \multirow{2}{*}{$\begin{array}{c}\rho_{\mathrm{uk}} \\
\left(\mathrm{mg} \mathrm{L}^{-1}\right)\end{array}$} \\
\cline { 1 - 1 } Metilen-hlorid, $\mathrm{pH}=8$ & \multirow{2}{*}{ I } & 133,6 & \multirow{2}{*}{173,5} \\
\cline { 1 - 1 } Metilen-hlorid, $\mathrm{pH}=2$ & & 39,9 & \\
\cline { 1 - 1 } n-pentan & \multirow{2}{*}{ II } & 213,6 & \multirow{2}{*}{387,1} \\
\cline { 1 - 1 } Dihlormetan & & 151,7 & \\
\cline { 1 - 1 } Dihlormetan, $\mathrm{pH}=2$ & & 21,8 & \\
\hline
\end{tabular}

Dobijeni rezultati (tabela 1) pokazuju da je vrednost ukupnog indeksa ugljovodonika u OSV po metodi T/T ekstrakcije sa metilen-hloridom manja 2,2 puta u odnosu na metodu sekvencijalne $\mathrm{T} / \mathrm{T}$ ekstrakcije sa n-pentanom, dihlormetanom i dihlormetanom pri $\mathrm{pH}=2$.

\subsection{Adsorpcija organskog opterećenja iz otpadnog sredstva za vlaženje}

Efikasnost i kinetička studija tretmana adsorpcije procenjene su na osnovu smanjenja koncentracije UOU iz OSV sa odgovarajućom dozom aktivnog uglja Norit w35 i u definisanom ravnotežnom vremenu adsorpcije.

U ravnotežnom vremenu adsorpcije od 360 minuta, efikasnosti uklanjanja UOU iz OSV za 20, 25, 30, 60, 80 i $100 \mathrm{~g} \mathrm{~L}^{-1}$ aktivnog uglja iznose: 36, 37, 38, 47, 58, 60\%, redom. Za efikasnosti uklanjanja veće $50 \%$, odabrane su: ravnotežna vrednost doze adsorbenta od $80 \mathrm{~g} \mathrm{~L}^{-1} \mathrm{i}$ ravnotežno vreme adsorpcije od 360 minuta (slika 1).

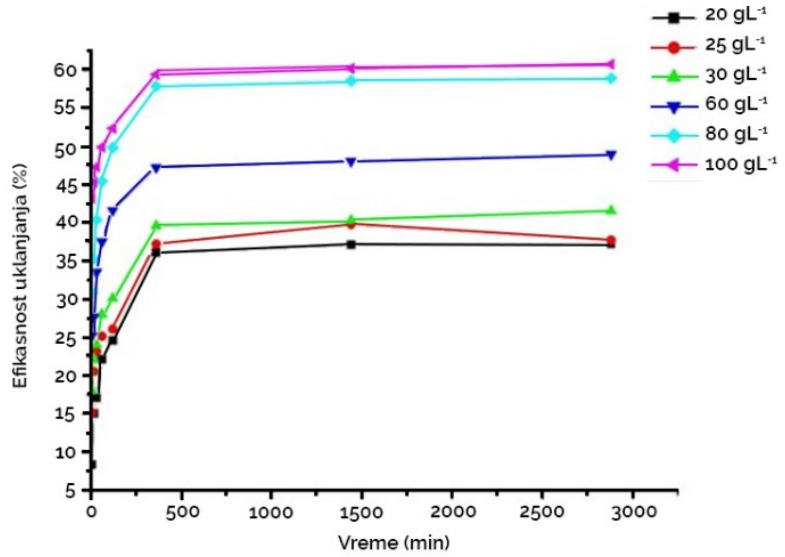

Slika 1. Zavisnost efikasnosti uklanjanja UOU iz OSV od vremena adsorpcije za različite doze aktivnog uglja Norit $w 35$

$\mathrm{Na}$ osnovu eksperimentalno dobijenih koncentracija $\left(\mathrm{C}_{\mathrm{t}} \mathrm{u}\right.$

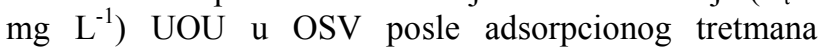
izračunate su: efikasnosti adsorpcionog uklanjanja $\left(\mathrm{E}_{\mathrm{AC}}\right)$ kao i parametri neophodni za konstruisanje grafika reakcionih kinetičkih modela adsorpcije: količine adsorbata po masi adsorbenta (ravnotežne, $\mathrm{q}_{\mathrm{e}}$, $\mathrm{i} u$ vremenu adsorpcije $\mathrm{t}, \mathrm{q}_{\mathrm{t}}$ ). Rezultati kinetike adsorpcije organskih supstanci iz OSV na aktivnom uglju Norit w35 za dozu $80 \mathrm{~g} \mathrm{~L}^{-1}$ i za adsorpciono vreme od 360 minuta prikazani su u tabeli 2 .

Tabela 2. Rezultati kinetike adsorpcije organskih supstanci iz OSV na aktivnom uglju Norit w35

\begin{tabular}{|c|c|c|c|c|c|}
\hline $\begin{array}{c}\mathrm{t} \\
(\mathrm{min})\end{array}$ & $\begin{array}{c}\mathrm{C}_{\mathrm{t}} \\
\left(\mathrm{mg} \mathrm{L}^{-1}\right)\end{array}$ & $\mathrm{E}_{\mathrm{AC}}$ & $\begin{array}{c}\mathrm{q}_{\mathrm{t}} \\
\left(\mathrm{mg} \mathrm{g}^{-1}\right)\end{array}$ & $\begin{array}{c}\ln \left(\mathrm{q}_{\mathrm{e}}-\mathrm{q}_{\mathrm{t}}\right) \\
\left(\mathrm{mg} \mathrm{g}^{-1}\right)\end{array}$ & $\begin{array}{c}\mathrm{t} / \mathrm{q}_{\mathrm{t}} \\
\left(\mathrm{ming}^{-1}\right. \\
\left.\mathrm{mg}^{-1}\right)\end{array}$ \\
\hline 5 & 1836,2 & 31 & 82,4 & 4,3 & 0,1 \\
\hline 15 & 1721,3 & 35 & 93,9 & 4,1 & 0,2 \\
\hline 30 & 1584,8 & 40 & 107,5 & 3,9 & 0,3 \\
\hline 60 & 1451,0 & 45 & 120,9 & 3,5 & 0,5 \\
\hline 120 & 1333,2 & 50 & 132,7 & 3,1 & 0,9 \\
\hline 360 & 1119,1 & 58 & 154,1 & 0,3 & 2,3 \\
\hline 1440 & 1101,0 & 59 & 155,9 & - & 9,2 \\
\hline 2880 & 1091,7 & 59 & 156,8 & - & 18,4 \\
\hline
\end{tabular}

Kinetički parametri pseudo-prvog i pseudo-drugog modela adsorpcije, izračunati iz nagiba i odsečka dobijenih pravih primenjenih kinetičkih modela adsorpcije i koeficijenti korelacije $\left(\mathrm{R}^{2}\right)$ za uklanjanja UOU (inicijalne koncentracije od $2700 \mathrm{mg} \mathrm{L}^{-1}$ ) iz OSV prikazani su u tabeli 3 . 
Za kinetički model pseudo-prvog reda linearna zavisnost $\ln \left(\mathrm{q}_{\mathrm{e}}-\mathrm{q}_{\mathrm{t}}\right) \mathrm{u}$ funkciji $\mathrm{t}$ daje visoko zadovoljavajuću vrednost koeficijenta korelacije $(0,996)$, ali je vrednost ravnotežnog adsorpcionog kapaciteta $(72,7)$ za dati model 2 puta manja u poređenju sa eksperimentalno dobijenom $\mathrm{q}_{\mathrm{e}}$ vrednosti (155,5 $\mathrm{mg} \mathrm{g}^{-1}$ ) (tabela 3). Visoka vrednost $\mathrm{R}^{2}$ pokazuje da se uticaj fizičke adsorpcije ne može zanemariti u procesu uklanjanja organskih supstanci iz OSV primenom aktivnog uglja Norit w35.

Tabela 3. Parametri kinetičkih modela za adsorpciju organskih supstanci iz OSV na aktivnom uglju Norit w35

\begin{tabular}{|l|l|c|}
\hline Kinetički model & Parametar & Vrednost \\
\hline \multirow{3}{*}{ Pseudo-prvog reda } & $\mathrm{k}_{1}\left(\mathrm{~min}^{-1}\right)$ & 0,01 \\
\cline { 2 - 3 } & $\mathrm{q}_{\mathrm{e}}\left(\mathrm{mg} \mathrm{g}^{-1}\right)$ & 72,7 \\
\cline { 2 - 3 } & $\mathrm{R}^{2}$ & 0,996 \\
\hline \multirow{3}{*}{ Pseudo-drugog reda } & $\mathrm{k}_{2}\left(\mathrm{~g} \mathrm{mg}^{-1} \mathrm{~min}^{-1}\right)$ & 0,08 \\
\cline { 2 - 3 } & $\mathrm{q}_{\mathrm{e}}\left(\mathrm{mg} \mathrm{g}^{-1}\right)$ & 157,5 \\
\cline { 2 - 3 } & $\mathrm{R}^{2}$ & 1,000 \\
\hline
\end{tabular}

Idealno slaganje između eksperimentalne i teorijske $\mathrm{q}_{\mathrm{e}}$ vrednosti (tabela 3) pokazuju linearnu zavisnost $t / q_{t} u$ funkciji $\mathrm{t}$ i koeficijent korelacije za kinetički model pseudo-drugog reda $(1,000)$.

$\mathrm{Na}$ osnovu dobijenih rezultata uočava se da je za opisivanje mehanizma adsorpcije organskih supstanci iz OSV na aktivnom uglju Norit w35 dominantan kinetički model pseudo-drugog reda. Takođe, za razliku od kinetičkog modela pseudo-prvog reda, model pseudodrugog reda predviđa ponašanje tokom čitavog procesa adsorpcije $\mathrm{u}$ ispitivanom adsorpcionom sistemu.

\section{ZAKLJUČAK}

Kvalitativnim GC/MS profilom OSV posle T/T ekstrakcije sa metilen-hloridom dokazano je prisustvo 31 organske supstance u OSV. Takođe, potvrđeno je prisustvo sledećih klasa jedinjenja u OSV: policikličnih aromatičnih ugljovodonika, alkohola, etara, ketona, fenola, supstituisanih benzena i derivata benzena, organskih kiselina, estra i amida organskih kiselina, organoazotnog jedinjenja i amina.

Posle sekvencijalne T/T ekstrakcije sa n-pentanom, dihlormetanom i dihlormetanom pri $\mathrm{pH}=2$, kvalitativni GC/MS profil pokazao je prisutvo 59 organskih supstanci OSV i sledećih klasa jedinjenja: viših alkana sa C20 do C30 atoma, nezasićenih alkena srednje dužine sa C10 do C20 atoma, alkohola, etara, ketona, supstituisanih benzena i derivata benzena, organskih kiselina, estara $i$ amida organskih kiselina, organoazotnih jedinjenja, organskih jedinjenja sa azotom i kiseonikom, organofosfornog jedinjenja, amina i steroida.

Dobijeni GC/MS profili pokazuju da se sekvencijalnom $\mathrm{T} / \mathrm{T}$ ekstrakcijom detektuje $47 \%$ više organskih supstanci u odnosu na T/T ekstrakciju sa metilen-hloridom. Takođe, PAH jedinjenja su detektovana samo T/T ekstrakcijom sa metilen-hloridom, dok su ugljovodonici i organska jedinjenja sa azotom i kiseonikom detektovani samo sekvencijalnom T/T ekstrakcijom. Zaključuje se da priroda rastvarača za ekstrakciju određuje klasu organskih jedinjenja koja će biti ekstrahovana.

Zbog razlika u GC/MS profilima dobijenih $\mathrm{T} / \mathrm{T}$ ekstrakcijom sa jednim rastvaračem i sekvencijalnom $\mathrm{T} / \mathrm{T}$ ekstrakcijom, a u cilju dobijanja profila sa većim brojem detektovanih organskih supstanci, konačan profil organskog opterećenja je zbirni profil GC/MS profila obe T/T ekstrakcione metode koji pokazuje da OSV sadrži 74 organske supstance sa verovatnoćom prisustva većom od $70 \%$ na osnovu AMDIS softvera za identifikaciju organskih supstanci i NIST referentne baze podataka.

Kvantitativni sadržaj organskih supstanci u OSV procenjen je na osnovu određivanja indeksa ugljovodonika. Dobijeni rezultati pokazuju da je vrednost ukupnog indeksa ugljovodonika u OSV po metodi T/T ekstrakcije sa metilen-hloridom manja 2,2 puta u odnosu na metodu sekvencijalne $\mathrm{T} / \mathrm{T}$ ekstrakcije sa n-pentanom, dihlormetanom i dihlormetanom pri $\mathrm{pH}=2$. Dakle, sa kvantitativnog aspekta smeša rastvarača za ekstrakciju (sekvencijalna) daje veće vrednosti ukupnog indeksa uglovodonika u složenom i realnom efluentu kao što je OSV.

Kvalitativna i kvantitativna karakterizacija OSV i vrednosti UOU (2700 mg L $\left.{ }^{-1}\right)$, HPK (1500 $\left.\mathrm{mg} \mathrm{L}^{-1}\right) \mathrm{i}$ BPK5 (810 $\left.\mathrm{mg} \mathrm{L}^{-1}\right)$ ukazuju na značajno organsko opterećenje efluenta procesa ofset štampe. Za smanjenje visokog organskog opterećenja OSV primenjen je tretman adsorpcije na aktivnom uglju Norit w35 čija je fikasnost $i$ kinetička studija procenjena na osnovu smanjenja koncentracije UOU iz OSV sa odgovarajućom dozom aktivnog uglja Norit w35 i u procenjenom ravnotežnom vremenu adsorpcije. Dobijeni rezultati adsorpcije pokazuju da u ravnotežnom vremenu adsorpcije od 360 minuta, efikasnosti uklanjanja UOU iz OSV za doze aktivnog uglja od 20, 25, 30, 60, 80 i $100 \mathrm{~g} \mathrm{~L}^{-1}$ iznose: 36 , $37,38,47,58,60 \%$, redom.

Dobijeni rezultati pokazuju da je moguće smanjiti organsko opterećenje iz OSV primenom adsorpcije sa aktivnim ugljem radi bezbednog odlaganja tretiranog ofset efluenta u grafičko okruženje. Međutim, u radu je postignuta maksimalna efikasnost adsorpcije organskih supstanci iz OSV od $60 \%$ na aktivnom uglju Norit w35. Kako je OSV složen, realni sistem i kako polarnost zagađujućih supstanci utiče na efikasnost uklanjanja, kombinacija aktivnog uglja sa drugim adsorbentom ili upotreba nekod drugog tretmana kao predtretmana adsorpciji svakako bi povećali efikasnost uklanjanja organskih supstanci iz ofset efluenta.

\section{LITERATURA}

[1] D. Povrenović, M. Knežević, “Osnove tehnologije prečišćavanja otpadnih voda”, Beograd, Tehnološkometalurški fakultet, Univerzitet u Beogradu, 2013.

[2] https://www.oxfordwebstudio.com/da-li-znate/sta-je-offsetstampa.html (Pristupljeno u oktobru 2018.)

[3] S. Adamović, "Elektrokoagulacioni i adsorpcioni tretmani efluenata u grafičkim procesima ofset štampe", Novi Sad,

Univerzitet u Novom Sadu, Fakultet tehničkih nauka, 2016.

[4] L. Dsikowitzky, J. Schwarzbauer, R. Littke, "Distribution of polycyclic musks in water and particulate matter of the Lip eRiver (Germany)", Org. Geochem., Vol. 33, pp. 1747-1758, 2002.

[5] ISO 9377-2 Method (2000): Water quality - Determination of hydrocarbon oil index - Part 2: Method using solvent extraction and gas chromatography.

\section{Adrese autora za kontakt:}

Jelena Karan - karankaran@hotmail.rs doc. dr Savka Adamović - adamovicsavka@uns.ac.rs Grafičko inženjerstvo i dizajn, FTN, UNS. 